\title{
Internal Control And Accounting Systems Documentation: A Case Study
}

Jeffrey E. Michelman, University of North Florida, USA

Bobby E. Waldrup, University of North Florida, USA

Melanie R. Gillman, PricewaterhouseCoopers, USA

\begin{abstract}
This case chronicles the experiences of a student intern as she assists in the transformation of a transportation company's internal audit department in a process to go public and come into compliance with the provisions of the Sarbanes-Oxley Act. It is designed to give students an inthe-trenches viewpoint of the sweeping effects that SOX has on the internal control structure of regulated firms. The topics of co-sourcing, documentation, re-performance, and mentoring are weaved into the story as examples of how the accounting profession affects organizational behavior and culture. The case is appropriate for undergraduate and graduate auditing, systems or internal audit classes. Moreover, the case would serve as an excellent aid for faculty and students involved in accounting internships.
\end{abstract}

Keywords: Sarbanes-Oxley; Mentorship; Internal Control; Internal Audit

\section{COURSES AND LEVELS FOR WHICH THIS IS INTENDED}

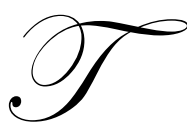

his case can be used to facilitate learning, as well as supplement a test and in-class discussions in undergraduate or graduate auditing, systems or internal auditing classes. Moreover, the case would serve as an excellent starting point for students and faculty involved in accounting internships.

\section{LEARNING OBJECTIVES}

1. The first objective deals with the importance of system documentation. This includes the overall concept of re-performance in audit work as well as the requirements of PCAOB AS No. 3: Audit Documentation. This objective will need to be adapted depending upon the class that the case is used in.

2. The second objective is to expose students to the real-world impact on an organization in attempting to come into compliance with Section 404 of the Sarbanes-Oxley Act. Moreover, this objective should help students to gain a better understanding of the impact of change on the profession of accounting/auditing and on the organizations that these functions operate within. This includes:

- Implementation Issues/Roadblocks

- $\quad$ Role of PCAOB

- Cultural and behavioral impacts of PCAOB implementation on the organization

3. The next objective pertains to the role of mentors in a organization. This deals more specifically with a mentor's role in the efficient acclimation of new staff in an organization.

4. The final objective is to address several organizational behavior issues that are affected by changes in accounting-related regulation. These include:

- The need and ability to enact change in an organization

- Written vs. Oral Communication

- Management's role in facilitating organizational change and communication

- This would be a important time to discuss the impact of SOX on non-covered organizations and the impact of rating agencies, state regulators and boards of directors on internal control system development and compliance. 


\section{CASE SYNOPSIS}

Since its passing, no legislation has had a more profound impact on the business community in the past 70 years than the Sarbanes-Oxley Act of 2002. Criticized tremendously for its significant and intrusive requirements on an organization, this paper explores those requirements from the trenches of an implementation effort. Additionally, it takes the perspective of an intern newly inducted into an organization and her efforts to navigate her matriculation through a 404 implementation.

\section{RESEARCH METHODS}

The third author was an audit intern at EntaMove while completing her Master of Accountancy Degree. Midway through her internship, the two faculty member co-authors met with the Director of Internal Audit and the Big 4 Internal-Audit Outsourcing Partner to discuss the possibility of completing a case study from an autobiographical point of view. All parties were very supportive of this project. Both the "Big 4" audit firm and the corporation were quite helpful in the development of the case, yet they have decided to have their names withheld at this point. As a result, the identity of all parties has been removed through the use of pseudonyms.

\section{EVIDENCE OF EFFICACY}

The case has been class tested in several sections of both Advanced Accounting Information Systems (Graduate) and Accounting Information Systems (Undergraduate). Four different faculty members at three universities were involved in the class testing process.

\section{INTRODUCTION}

On the brief drive to her Beta Alpha Psi meeting, Melissa Smith, a graduate accounting student at the Sunshine State University (SSU), pondered what possible insight she could give her impending audience. It was Tuesday, January 15, 2010, and Smith had been asked by her professor to share her most recent internship experience; more specifically, how her prior education had prepared her for her current duties and what specific lessons she had learned.

For Smith, taking an Internal Audit intern position at EntaMove, a transportation company in the process of going public on the New York Stock Exchange, had presented a rare opportunity for academic studies to meet practical application. As a company aspiring to become publicly traded, the main focus of the EntaMove internal audit department was to move the company into compliance with the section 404 provisions of the Sarbanes-Oxley Act of 2002 (SOX).

Smith had been well-read on the Sarbanes-Oxley Act of 2002 through her class studies; however, actually participating in implementing the Act had presented a much greater challenge. She remembered, prior to starting her internship, hearing about the difficulties that companies everywhere were having with implementation efforts and she was sure EntaMove would be no exception. As Smith pulled into the SSU parking lot, she remembered the challenges she had overcome in the previous five months. She pondered the extent to which her professional, personal and technical skills had been challenged. Finally, she wondered how best she could convey her experiences to her fellow students, hopefully imparting the knowledge she had obtained on her audience.

\section{ENTAMOVE-AN ORGANIZATION OF CHANGE}

Melissa remembered how excited she felt when she first got the phone call. EntaMove, a transportation company with a market capitalization of over 1.1 billion dollars and 3,000 employees, had offered her a plum internship in the Internal Audit department located in their corporate offices. The director had called to make the offer himself. He explained that the department was undergoing drastic changes as a result of the decision to go public, and her internship would not involve copying and making coffee; this was the big leagues. 
Prior to her arrival, EntaMove's Internal Audit (IA) department was undergoing a plethora of changes; essentially a re-organization of sorts. Before the recent decision, IA focused mainly on compliance and operational based audits. The purpose of the IA department focused heavily on cost savings and operational efficiency, rather than a thorough assessment of EntaMove's control structure. Prior to the need to be in SOX compliance, EntaMove had undergone a massive corporate restructuring. The IA Department had been one of the hardest hit. Part of the restructuring involved a significant reduction in headcount for the department from 20-25 members to a total of 5, an effective decrease of $70-75 \%$.

Some of the operational audit work had been considered duplicative within the organization, or was thought to be better positioned elsewhere. For example, Six Sigma and Profit Improvement Teams were thought to be a better "cure" than operational audits; audits that seemed to report the same problems year after year. Also, revenue invoice auditing was thought to be better placed reporting to the VP responsible for Customer Service. The thinking being that there would be a better probability of correcting billing problems if found through the audit process. As a result, these changes helped to redefine Internal Audit at EntaMove. As part of this process, management selected a member of the financial reporting team to head up a newly defined internal audit program.

The newly found need to be SOX compliant resurrected the purpose and drive behind IA. A significant dynamic of SOX was the resultant additional weight given to the importance of a company's IA department. EntaMove's management would now be required to assess and report on their internal control structure, a task guaranteed to be taxing both financially and in terms of human capital. Given SOX's stringent requirements on the IA department, combined with the deficiency in workforce, EntaMove's management felt it important to enlist the aid of a "Big 4" accounting firm, C\&A. One increasingly popular way of incorporating a "Big 4" firm is to initialize a Co-sourcing effort. While the outsourcing of business activities has long been a common business practice, Cosourcing allows a company to "partner" with an outside firm, incorporating their own staff with that of the consulting firm to work toward a common objective. Although not familiar with co-sourcing, Smith soon learned that working with C\&A during the implementation would allow EntaMove to leverage the expertise of a firm with a wealth of experience in internal control development. In addition to development efforts, the firm would also be a critical resource for documentation and testing initiatives.

With the addition of C\&A to their roster, EntaMove began developing an implementation plan for the Section 404 provisions of SOX. From a high level perspective this would include a four tier implementation program including: 1) development and documentation of the internal control structure, 2) "walkthroughs" and refinement of internal controls, 3) testing of controls, 4) review and analysis. Melissa began to think back to her accounting information systems class where she first started to examine transaction processing systems and applying internal controls to them.

\section{DEVELOPMENT AND DOCUMENTATION}

EntaMove and C\&A knew that in order to understand and begin assessing their control structure, structure would first have to be thoroughly documented and detailed. The team began by analyzing the core of EntaMove's business, effectively dividing operations into a series of business processes. These processes essentially were composed of several pre-defined activities, working together to meet the goals of the organization. Subsequent to this, the processes were analyzed to determine and (perhaps more importantly) document those controls inherent in the process. This proved demanding at best, as never before had documentation of this magnitude been attempted. Yet Smith recalled just how exciting it had been to be involved in an accounting activity that was just in its infancy. The documentation process involved the development of narratives and flowcharts for the process. Narratives describe the process in a written format, while flowcharts offer an illustrative perspective; both proved invaluable as a framework for the test plan and guidance for testing procedures. Smith recalled having to do flowcharts in her accounting information systems class, but never thought that she would have to use them.

\section{WALKTHROUGHS AND REFINEMENT OF INTERNAL CONTROLS}

Smith began her internship in August 2009, with EntaMove seemingly well underway in their implementation efforts. She would soon learn that EntaMove was a little behind in their implementation schedule. 
Moreover, both EntaMove and C\&A were developing their Audit Plan for the first time. Her internship offered her both a tremendous opportunity and something that scared her more than a little. To her, internal controls were really only something that she had read about in textbooks. After all, she now felt that through the requirements set forth under SOX, she had a clear responsibility to make sure that the Internal Control system protected the rights of shareholders. What would happen if the control systems did not meet the auditor's expectations; suppose she missed something? Of the business processes within EntaMove's operating structure, over two hundred controls had previously been identified for documentation and testing. Smith began working for EntaMove after the related process controls had already been identified and documented. Her major role would now be to begin testing the effectiveness of the identified and documented controls within the company's process structure.

EntaMove had previously documented controls through a series of "walkthroughs." During these walkthroughs, an individual would retrace the business process, observing and documenting along the way how the controls in place worked. By using the documentation obtained through the walkthroughs, Smith could begin testing the processes assigned to her.

\section{TESTING OF CONTROLS}

There was little time to ride the learning curve for Smith. In fact, her first day at EntaMove, she was given the Equity Investments process and sent to begin testing. She was in the door at 9 a.m., and by 10 a.m. she was speaking with the "process owner" (PO) of equity investments at EntaMove. The concept of controls testing seemed overwhelming at first, however, Smith was comforted by the idea that even seasoned auditors were relatively new to the requirements set forth by Section 404. Since everything was so new, all Smith could rely on was PCAOB Auditing Standard No. 2: An Audit of Internal Control Over Financial Reporting Performed in Conjunction With an Audit of Financial Statements to help her understand what she was supposed to accomplish. Further, Smith found that guidelines for documentation were limited to PCAOB Auditing Standard No. 3: Audit Documentation and the guidelines set forth by EntaMove, Smith found that all the resources needed to be an effective part of the implementation efforts were at her disposal, yet there were no people around who had done this before. To a certain degree they were all making the audit plan up together as they went. Additionally, there were co-workers at every step ready to help Smith with any concerns, but unlike previous testing of internal controls, Section 404 had a new focus with new expectations. Still, she couldn't seem to overcome the burden associated with the vast importance of the tasks she was to perform. Smith knew that she would have to thoroughly test and evaluate EntaMove's controls in order to ensure their effectiveness. Any deficiencies would have to be identified and fixed before EntaMove's management could attest to the effectiveness of their controls. Moreover, the external auditors would be vigorously testing EntaMove's controls and scrutinizing the work done by the internal auditors. Thus, Smith knew, even as an intern, that her work would be crucial to EntaMove's compliance efforts.

\section{Mentoring}

Smith felt pressure not only to perform but also to understand the process. Moreover, she quickly understood that it was important to scrutinize the process carefully, yet she always knew that there was a schedule and there was a need to stay on it. It was important for her to identity those individuals who, at anytime, could act as a support system and address any unforeseen issues. Unfortunately for Smith, there was no system in place to provide her with a definitive individual assigned as her mentor. Understanding the importance of the mentor relationship, Smith focused on developing close relationships with fellow employees; people she could look up to as guides for her implementation journey. Relationships were formed not only within IA but also with the individuals she interacted with while undergoing her testing efforts. She would develop relationships within the IA department that would allow Smith to ask questions and, if needed, relate to those individuals whose years of experience in the organization would help Smith overcome any potential obstacles. Along with building mentor relationships within the IA department, it was equally important to build a relationship with her co-workers from C\&A. Both relationships were important in that they allowed for learning and understanding from all sides of the spectrum. Although Smith felt good about her technical abilities she still did not feel prepared to apply them in the field. She thought about the group projects that she used to hate. Her job had become a series of constantly changing group projects; sometimes the team was the same and at other times it changed. Moreover, she continued to find that things were not clearly defined. She never thought that accounting contained so much ambiguity. 


\section{Daily Activities}

While Smith's primary role would be to aid in the testing of EntaMove internal controls, she soon learned that this was simply one aspect of her responsibilities. In order to successfully test a process, she would have to first understand it. This meant reading the prior walkthrough documentation, as well as meeting with the corresponding POs. In order to ensure employee ownership over the implementation, POs were assigned to each identified process. The POs held the responsibility of ensuring that the processes, as well as the controls therein, operated the way they were intended. While internal auditors would have to work closely with POs to ensure that the processes were documented properly, POs also represented a vital resource to aid the internal auditor in control testing. Auditors would look toward the POs to help obtain the support necessary for testing purposes.

Thus, Smith's work would begin with studying the process, meeting with the POs to further enhance her knowledge of the process, and then begin the testing procedures. Figure 1 illustrates the generalized process associated with the POs.

EntaMove had developed guidelines on how the controls should be tested, detailing the extent and timing of controls testing. Smith could use this reference guide to aid her in determining the appropriateness of her testing procedures, as well as allowing her to make any necessary adjustments along the way. Smith knew that certain elements inherent in the control procedure would impact the extent of testing required for that control. Characteristics such as the frequency, complexity, and importance of the control all impact how the control would ultimately be tested. Beyond the reference guide, Smith also had a myriad of co-workers available to field any questions she would have. There would also be several large processes that she would test with other internal auditors including C\&A. Smith would have ample resources available to her for testing purposes, and she would need to exploit every one of them.

During the testing phase, Smith would have to document her work as she performed her testing procedures. This would include following both EntaMove's and the PCAOB's guidelines while she tested ${ }^{1}$. Given the stringent requirements before her, Smith was initially worried that the required amount of documentation would be overwhelming relative to the amount of detail and time required to correctly document the process. She knew that the testing she performed could be perfect; however, if it was not documented properly, all of her work would be in vain. Thus, she felt added pressure to ensure that her documentation not only met but exceeded the guidelines set before her.

\section{Issues/Roadblocks}

As she began her work in the implementation process, some immediate issues became apparent to Smith that threatened to thwart her progress. First, she soon realized that getting the POs to find time to talk to her was a feat in itself. The POs had responsibilities related to their everyday jobs, and as such the SOX implementation efforts would inevitably come second to their daily responsibilities. Thus, Smith realized that she would have to arrange times to meet with the POs that not only incorporated the PO's schedules, but also allotted Smith enough time to complete the required testing given her time constraints. Additionally, simply scheduling meeting times did not necessarily mean that the meeting would take place. Many times, problems would arise that would result in the PO either rescheduling the meeting or simply not attending. Smith quickly learned that although everyone was always polite to her, they also knew that she was an intern and would be gone in six months. As a result, Smith would have to develop flexible time management, completing the tasks that she could, while she could. Smith had to learn to identify back-up work, tasks that she could complete if the meetings she scheduled fell through. Doing this would ensure that Smith continued to use her limited time efficiently, even when her original plans failed. She quickly learned what her professors had referred to in class as the importance of multi-tasking. Moreover, her time management skills were being pressed to their limits.

\footnotetext{
${ }^{1}$ Smith quickly learned that the PCAOB website would be a major resource when questions arose. http://www.pcaobus.org/index.aspx
} 


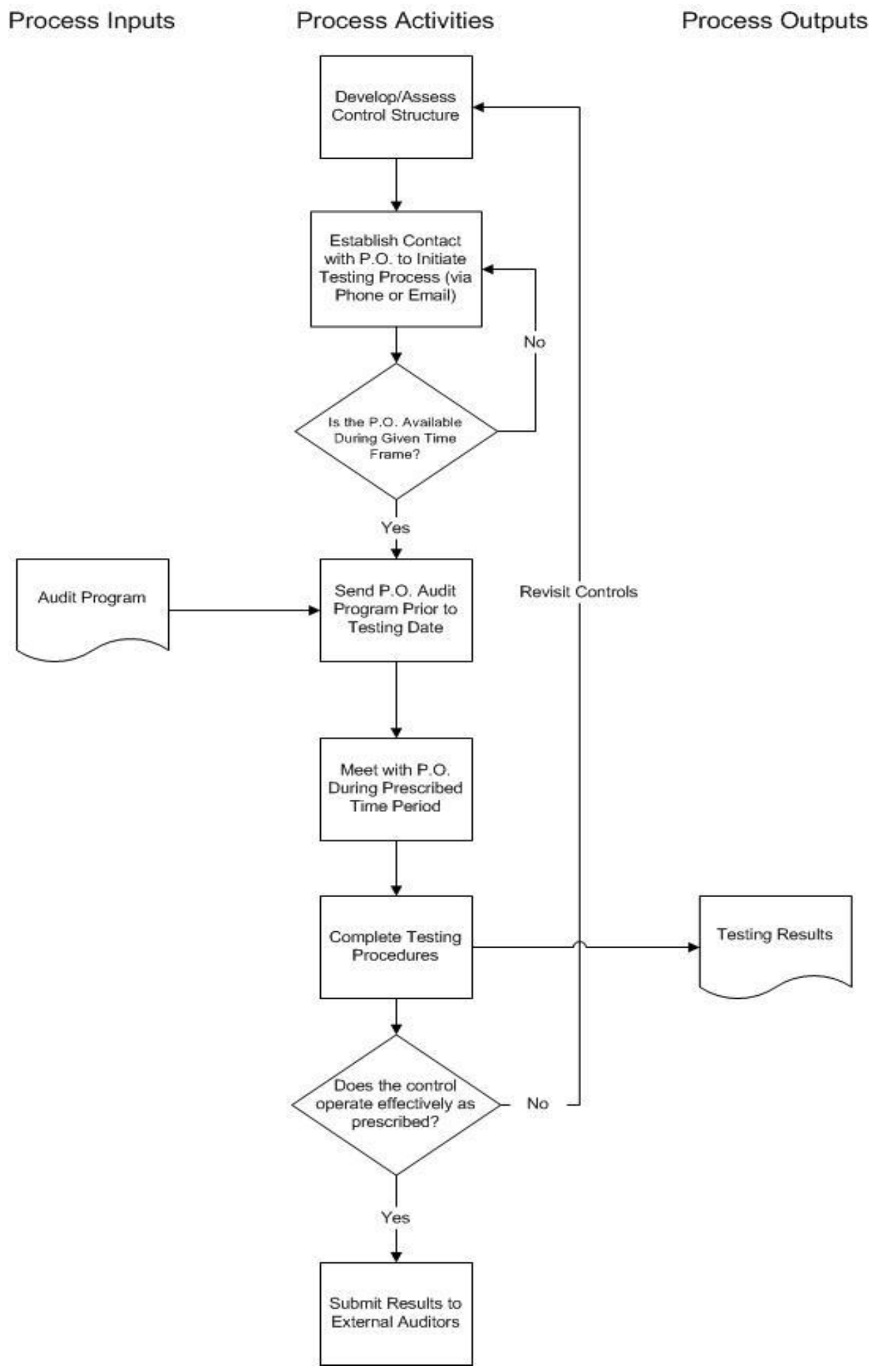

Figure 1: Flow Chart of Activities with Process Owners (P.O.) 
While many of the POs genuinely were plagued with limited time to meet with auditors, a few simply failed to understand the importance of the process. As a result, Smith got the impression that some POs were simply "blowing her off." This made it extremely difficult to obtain the information she needed from the POs, while still following the stringent implementation time-table. She would arrange meetings; however, they would be continually cancelled. This presented a distinct challenge for Smith, as she would have to find a way to complete her assigned work regardless of the roadblocks presented before her.

Luckily for Smith, EntaMove's management caught wind of the potential problem and implemented a program to further hold the POs accountable for their process' role in the implementation. Departments were rated, for the entire organization to see, by the testing progress that was accomplished in that particular area. The results would be presented to the Implementation Team, which consisted of the audit committee as well as the internal and external auditors, in their bi-weekly meetings. The Implementation would allow for an in depth review of the areas behind schedule and investigate by inquiry all parties involved in the issues related to the identified area. In doing so, the PO would be informed if there was evidence of excessive delays or other issues. This allowed for remediation of implementation issues at a higher managerial level, a top-down "motivation" to ensure progress continued as efficiently as possible. When Smith learned about management's new strategy for getting the "process owners" to buy-in, she felt that these same managers would now treat her questions with the significance that was required.

While her experiences with arranging meetings varied from PO to PO, Smith soon realized that a face to face meeting was simply one element in the information gathering process. Given the issues Smith had with the POs, she knew that when she was in her meetings, time was of the essence. As a result, she realized that she would have to learn to ask the right questions, making the best of the little time she was granted. Most importantly, she realized that she needed to do her research before meeting with the POs. Wasting time would prove both frustrating to the PO, as well as Smith. Asking the "right" questions required Smith to be prepared before the interview, using the previous walkthrough documentation to thoroughly study the process and have extensive questions prepared prior to the meeting. At first this made her really nervous, but she quickly realized that the POs knew when she had done her homework and responded accordingly. Additionally, Smith found that she needed to be prepared to respond to the answers she received, keeping in mind the purpose behind her meetings and the goals she needed to achieve. This would minimize her need to continually contact the PO and ask time consuming follow-up questions.

Documentation presented another, more complex hurdle for Smith as she continued her testing efforts. Oftentimes control testing involved numerous intricate activities, all of which needed to be documented. She knew that her documentation had to be thorough enough to capture all aspects of the testing she performed; however, Smith knew that she couldn't afford to spend all her time documenting testing procedures and results. Those above her would need ample time to review her work, and decide if the results of the testing indicated any control deficiencies. Smith found that it was often difficult to balance the fine line between lengthy, inefficient documentation and documentation that lacked adequate description. Smith would have to ensure that she learned from any early mistakes, incorporating feedback into her future work.

\section{REVIEW AND ANALYSIS}

One major roadblock that presented itself was the process of review employed by the IA department; a process which, in theory, seemed effective. Smith would soon realize, however, that this assumption was unwarranted. The review process started with the submission of testing results for controls within a particular process, to an assigned IA manager. The paperwork submitted included the narrative of the process, the test results and the internal control matrix (ICM). This form of submission allowed for the manager doing the review to remain competent and command a full understanding of the control. This, however, proved a significant bottleneck at the managerial level. Managers were often swamped with other controls to review, or other roadblocks including subsequent control revisions. Once reviewed, results and comments were sent on to the Director of IA or a senior level manager for a higher level review. At this level, the major issue proved to be turnaround time to the external auditor and, if need be, back to the internal audit department or the individual who performed the testing. In most cases, the tested control would then be sent back down the chain to IA for identified changes and deficiencies associated with testing. This could take up to two weeks and, by that time, time constraints had forced the internal 
auditor to move on to test another process. Smith would then be forced to halt her current tasks to address issues that had previously been tested, which proved taxing on both Smith's memory and time. It not only took extensive time management skills, but also extreme patience when dealing with the POs who no longer wanted to be "bothered" by the auditors.

\section{FIXED ASSETS - AN EXAMPLE}

One of the earlier processes that Smith found herself working on was dealing with the purchase of Fixed Assets. When starting at EntaMove, the narrative and flowchart of the process related to fixed assets was already complete. Smith found herself reviewing the walkthrough documentation for this process, which included the firm's policies and procedures (Figure 2), details of the individuals involved, examples of important documents, and, of course, the narrative and flowchart.

\section{EntaMove Policies and Procedures}

Purchase of Fixed Assets

Effective: Jan 2004

- Fixed Asset purchases $>\$ 500$ require a purchase order

- Purchase Orders must be signed by the appropriate manager

- Fixed Asset purchases $>\$ 1,500$ require 2 written quotes

from separate vendors

- See Policies for Purchases and Payables for additional guidelines governing the purchase of fixed assets

Figure 2: Policies and Procedures Related to Fixed Asset Purchases

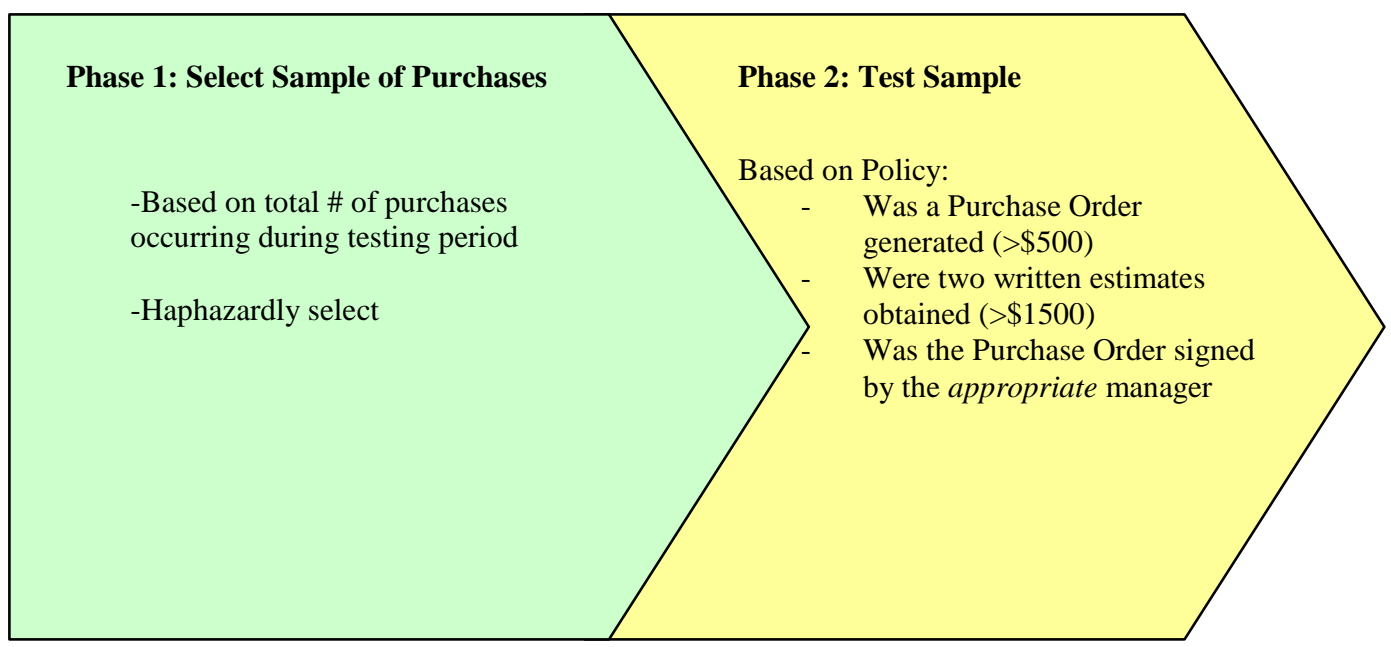

Figure 3: Testing for Fixed Asset Purchase

Smith noted in her testing plan that the first process control she would need to test related to one of the more, in her mind, simple aspects of the fixed asset purchasing cycle. To ensure the validity of fixed asset purchases, any purchases greater than $\$ 500$ required a purchase order, which required the appropriate manager's signature. Thus, her testing would consist of two phases which are outlined in Figure 3. First, she would have to determine her sample size. EntaMove and C\&A had guidelines for determining the required sample sizes, which, for this particular control, would be based on the total number of purchases processed during the period. For the 
purposes of testing these controls, the population was defined by the number of transactions or the number of times a control was performed annually. Thus, in this case, the number of transactions, rather than dollar values, was used for the basis of selection. Because the testing was focused on controls, the testing was more concerned with obtaining comfort over the process effectiveness rather than the balance. The use of dollar consideration was generally made only when understanding the magnitude of an exception (i.e., any variance above a certain dollar limit would be considered an exception).

In order to obtain the necessary information, Smith would have to go through the POs in a process similar to that described in Figure 1. She looked through her testing program, noting that Devon Charles, the Fixed Assets Manager, was the corresponding process owner. Charles' office was located across town, so Smith knew she would have to arrange a meeting time for the following day. The following chain of events took place. the second ring.

Smith picked up the phone and dialed the extension she had found for Devon Charles. He picked up on Devon Charles.

Mr. Charles. Good morning, this is Melissa Smith from Internal Audit. Do you have a minute?

There was a slight pause. Yes, Ms. Smith?

As I'm sure you are aware, we are required to verify control procedures in our ongoing effort to come into compliance with the Sarbanes Oxley Act. I need to perform a test on fixed asset purchase orders, and you are the process owner for this area.

There was a sigh at the other end of the line. Yes, yes, Ms. Smith, we are all aware of the process. Maybe one day we can get back to doing something useful. What do you need from me now?

Melissa caught the edge in his comment, but she was learning to exert an air of infinite patience with the process owners. Like a hospital patient having endless intrusive tests performed upon them, the process owners were growing understandably weary of this testing. Mr. Charles would undoubtedly be doubly irritated when he realized that Melissa was only an intern in the company.

Thank you for your patience, Mr. Charles. I know it's an intrusion. I have a set of purchase orders that I need to verify signature compliance on. If I email the purchase order numbers to you now, can you meet me in the morning at, say, 8 a.m. first thing so that it doesn't intrude too much into your schedule?

Devon Charles softened a bit. Sure. Shoot me the numbers, and I'll get them together for the morning.

Melissa emailed the purchase order numbers that she needed to verify. This email included a confirmation of the agreed upon time, the testing program, and a list of what Smith would need (including the list of purchases).

The next morning, at 7:45, Smith was on location and waiting for Charles. Around 8am, Charles arrived, ready with Smith's request which he had prepared the evening before. He handed Smith a system generated report which detailed the total amount of fixed asset purchases during the year. From here, she counted the number of purchases and determined her sample size, as illustrated in Figure 3.

Once determined, she used the haphazard ${ }^{2}$ sample selection collection method from the data detail and began Phase 2 of her testing. Smith submitted her selections to Charles and waited for the supporting documentation for the purchases (purchase orders, estimates, etc). Once she received the documentation for her selections, she reviewed the supporting documentation for conformance with policy. Specifically, if the purchase was $>\$ 500$, she looked for a purchase order that was signed by management. If the purchase was $>\$ 1,500$, she would look for a signed purchase order and two written estimates. Finally, Smith ensured that the appropriate manager signed the document. This required Smith to identify the signer, identify the area of use, and then review

2 c.f. Arens et. al (2006) for a description of this sampling technique. 
the organizational chart of the company to determine whether the manager had the authority to sign for the purchase. After a thorough review, Smith was able to confirm that indeed all of her selections conformed to EntaMove policy. If any of her tested selections deviated from the policy (i.e. no signed purchase order for a purchase $>\$ 500$ ), this would be considered an exception.

Similar procedures were required for other controls in the process. Often, Smith would have to submit requests for support in ample time, as the information gathering process could prove to be time consuming. Thus, Smith would often attempt to obtain the detail required to make selections in advance, enabling her to initiate her requests early. After her testing was complete, Smith recorded the Fixed Asset testing results and any exceptions that were noted in an Excel spreadsheet. This was then combined with the results from the other tested controls, as well as the process narrative and flowcharts, and subsequently submitted for review.

\section{REFLECTION}

\section{Lessons Learned}

The Beta Alpha Psi meeting would be starting soon; Smith gathered her thoughts on what her experience had taught her. There were, of course, the obvious technical abilities that Smith developed while working. She came away from the experience with a much more profound understanding of internal controls, and their role in ensuring the accuracy of financial information. While in-class assignments offered a basic understanding of internal controls, Smith's time at EntaMove allotted her a much more practical understanding of how controls actually work (and sometimes fail to work). Smith realized that there is no replacement for time spent "in the trenches," testing and developing actual controls. These experiences, Smith felt, would enable her to bring greater depth and knowledge into the remaining time she would spend in graduate school.

With this in mind Smith began to reflect on how her education had prepared her for such an experience. Prior to her arrival at SSU, she had received her Bachelor's of Science in Accounting from Florida Citrus University. It had become apparent to Smith that most of her knowledge and preparation for the internship came from the work she performed within her graduate program. At this stage she had been exposed to a higher level of understanding related to SOX, than in-class discussions and assignments that required her to obtain command of the material. Somewhat surprisingly, Smith thought about how understanding transaction processing and how to document the controls was critical for her to be able to actually test the controls. Even still, this had not fully prepared her for the detail involved in actually participating in an internship of this nature. Her schooling had acted solely as a stepping stone, in her journey into internal auditing.

Compounding her work pressures, Smith also found herself juggling a full course load while working at EntaMove. With average of thirty hours a week, it became apparent that neither her school work nor her work requirements could take precedent over one another. Indeed, she would have to effectively juggle both requirements. One advantage that soon revealed itself, however, was that she could incorporate her daily knowledge from school with the daily knowledge acquired from her internship. The resultant effect was synergistic in nature, as concurrent exposure enabled Smith a deeper understanding than what might have otherwise been achieved.

Smith had also learned several other key lessons that were applicable to her personal and professional development. During her testing, very few of EntaMove's employees she relied on had a background in auditing, and a few even lacked a basic accounting background. As such, Smith had to learn to "translate" much of her auditing and accounting language to that which the POs and others could easily understand. Much of the financial statement assertions, for instance, would need to undergo this translation for Smith to convey her message to the POs. Smith understood that this ability would be something she would have to revisit over the course of her career as an auditor, whether internal or external.

Finally, there were several broad level observations that Smith made relative to ensuring a successful 404 implementation. While seemingly obvious, many implementation efforts have been substantially thwarted by a lack of adequate communication. Throughout the implementation, Smith realized how thoroughly committed EntaMove was to their communication efforts, both internally and externally. While dealing with employees within the 
organization, EntaMove employed numerous tactics to ensure that progress and any changes would be efficiently and effectively communicated. EntaMove also placed significant importance on communicating with their external auditors. Since the external auditors were concurrently testing EntaMove's internal controls, it was imperative that any significant issues be quickly communicated to the external auditors. This was accomplished through mandatory meetings twice a month, along with any additional meetings scheduled as needed. Smith also observed a commitment to excellence that permeated through the entire implementation team. Oftentimes, especially with deadlines around the corner, the temptation to cut corners arose in efforts to complete the task at hand. Smith found that despite such temptation, the integrity of the implementation would remain uncompromised. The desire by upper management to maintain a maximum level of quality in the implementation far overshadowed any potential for lackadaisical effort. The examination of the controls for both 404 compliance and financial statement assertions was finally starting to make sense.

\section{PRESENT DAY}

As Smith stood to walk toward the podium, her thoughts again rested on her matriculation through the 404 implementation. She looked at her notes, but was this really what she wanted to say? She did not want to pass up such a good opportunity to explain what a great experience she had had, but she also wanted to make sure that students were prepared. EntaMove was wrapping up their implementation efforts, documenting last minute issues, and planning for testing during the next fiscal year. Smith, however, couldn't help but think about the profound difference that she noticed relative to EntaMove's relationship with their external auditors. The SOX requirements of publicly traded companies were stringent on all parties involved, and as a result the external auditors found themselves at EntaMove on a more regular basis. Additionally, the external auditors were able to obtain a much more profound understanding of EntaMove and their operations, based on the testing and documentation required for the internal control assessment process. This inevitably resulted in a more efficient and effective external audit, a scenario which was pleasing to both the client and the audit firm. Moreover, she could not help but notice a level of competition between C\&A and the "Big 4" external auditor, WCG.

Smith knew she had had a year to reflect on the internship. After the internship and graduation, she had accepted permanent employment with C\&A's internal audit outsourcing group in her hometown. Whether internal or external auditing, Smith had received an educational experience with practical application. She felt confident that the opportunity to participate in a 404 implementation had proved invaluable in her as a first year staff. There were, however, several questions that continued to plague Smith in the seconds before her speech. What could she have done to better prepare for her experience? Granted, she had gone through a rigorous undergraduate and graduate program, but she none-the-less felt overwhelmed when she started working at EntaMove. There were undoubtedly a plethora of resources available that she had overlooked. Additionally, what was the core, underlying lessons Smith could take with her? Granted she had received substantial exposure to her future career, but what good were her experiences if she couldn't at least minimally quantify them. Finally, how did the internship prepare her for her first year at C\&A.? She had to leverage off the friendships she initiated, however, she couldn't help but think that having someone there her first day at EntaMove would have made the cultural transition easier. All these thoughts, however, soon drowned out as she heard her name called from the podium microphone. She walked up to the podium, her hands were shaking. There were at least 150 students sitting out there waiting for her. It was now or never....

\section{AUTHOR INFORMATION}

Dr. Jeffrey Michelman is a Professor of Accounting and Director of the Flagship program in International Business. He was selected as the runner-up for the University of North Florida's Distinguished Professor Award in 2011. Dr. Michelman is both a CPA and CMA. He has published articles in a variety of information systems, accounting, international business and healthcare journals. Dr. Michelman lectures extensively to practitioners on Sarbanes-Oxley, Internal Control, Corporate Governance, Disaster Planning, Accounting Fraud, the Internet and the overall use of Accounting and Technology in Healthcare and other service organizations. E-mail: jeff.michelman@unf.edu 
Dr. Bobby E. Waldrup is an Associate Provost and Professor of Accounting at the University of North Florida. Dr. Waldrup is a CPA, and has published numerous articles in the area of managerial and fraud related accounting topics. Dr. Waldrup has also taught continuing professional education to over one thousand accountants. E-mail: bwaldrup@unf.edu.Corresponding author.

Melanie Gillman is an Experienced Manager for PricewaterhouseCoopers (PwC) LLP. She holds a BS in Accounting from the University of Florida and her Macc from the University of North Florida. She has provided expertise in process, risk and controls for her clients. Melanie currently specializes in Internal Audit Services; specifically Sarbanes-Oxley compliance, enterprise risk management, process improvement and redesign for various client industries, including Healthcare, Transportation and Logistics and Retail and Consumer. Melanie has provided Sarbanes-Oxley leadership and support for a multitude of national and multinational companies as well as led and deployed training in these areas. E-mail: melanie.r.gillman@us.pwc.com

\section{REFERENCES}

1. Braiotta, L. (2004) The Audit Committee Handbook, (New York, NY: John Wiley).

2. Bozeman, Barry \& Feeney, Mary K. (2007). Toward a Useful Theory of Mentoring: A Conceptual Analysis and Critique. Administration \& Society, 39(6), 719-739. Retrieved February 21, 2011, from ABI/INFORM Global. (Document ID: 1340652811).

3. Bulkeley, W. and Tomsho, R. (2005) Kodak to Get Auditors' Adverse View, The Wall Street Journal, January 27, A3.

4. Chambers, R. and Moscrop, K., (2005) How to rebalance internal audit priorities in the Sarbanes-Oxley era. PricewaterhouseCoopers.

http://www.pwc.com/Extweb/pwcpublications.nsf/docid/07D11E01F3A2D1C785256FD30004A331

5. Chreim, S. (2002) Influencing organizational identification during major change: A communication-based perspective, Human Relations, 55:9, 1117-1137

6. Colbert, Janet. (2005) The New Audit Documentation Requirements, Implications for Internal Auditors Internal Auditing. 20:1; 11-27.

7. Connelly, J. (2003) Next On The Griddle: Nonprofit Boards, Corporate Board Member, http://www.boardmember.com/issues/archive.pl?article_id=11729, (November/December).

8. Dirsmith, Mark W., \& Covaleski, Mark A.. (1985). Informal Communications, Nonformal Communications and Mentoring in Public Accounting Firms. Accounting, Organizations and Society, 10(2), 149. Retrieved February 21, 2011, from ABI/INFORM Global. (Document ID: 1908921).

9. Herbohn, K. (2004) Informal Mentoring Relationships and the Career Process of Public Accountants, The British Accounting Review. 36:4, 369-393

10. Joiner, T., Bartram, T. and Garreffa, T. (2004) The Effects of Mentoring on Perceived Career Success, Commitment and Turnover Intentions, Journal of American Academy of Business, 5:1/2; 164-170.

11. Levitt, A. (2002) Take on The Street, (Pantheon: New York, NY).

12. Naumes, W., \& Naumes, M. J. (2006). The Art and Craft of Case Writing. Armonk: NY: ME Sharpe.

13. Ortiz-Walters, R. (2009). Mentorship Collaborations: A Longitudinal Examination of the Association with Job Performance and Gender. The Journal of Business and Economic Studies, 15(1), 26-47,110. Retrieved February 16, 2011, from ABI/INFORM Global. (Document ID: 1705179671).

14. Paul, J. (2005) Exploring PCAOB Auditing Standard 2: Audits of Internal Control, CPA Journal (May).

15. PCAOB (2004) Auditing Standard No. 2: An Audit of Internal Control Over Financial Reporting Performed in Conjunction With an Audit of Financial Statements, http://www.pcaobus.org/Rules/Rules_of the Board/Auditing_Standard_2.pdf

16. PCAOB (2004) Auditing Standard No. 3: Audit Documentation, http://www.pcaobus.org/Rules/Rules_of the Board/Auditing_Standard_3.pdf

17. Pfeffer, J. (1981) Management as symbolic action: The creation and maintenance of organizational paradigms. In Cummings, L. and Staw, B. (eds).Research in Organizational Behavior. Greenwich, CT: Jai Press, 1981, 3, 1-52

18. PricewaterhouseCoopers (2005) How to move your company to sustainable Sarbanes-Oxley compliance from project to process. http://www.pwc.com/Extweb/pwcpublications.nsf/docid/07D11E01F3A2D1C785256FD30004A331 
19. Public Accounting Report. (January 15, 2006). Aspen Publishers. Aspen, CO.

20. Public Company Accounting Oversight Board (2004) Auditing Standard 3: Audit Documentation, 302-328.

21. Ribstein, L. (2002) Market vs. Regulatory Responses to Corporate Fraud: A Critique of the Sarbanes-Oxley Act of 2002, Journal of Corporation Law, 28:1, 1-67.

22. Sarbanes Oxley-Act of 2002, (2002) http://www.pcaobus.org/About_the_PCAOB/Sarbanes_Oxley_Act_of_2002.pdf

23. Sellers, R. Drew \& Fogarty, Timothy J. (2010). The making of accountants: the continuing influence of early career experiences. Managerial Auditing Journal, 25(7), 701-719. Retrieved February 16, 2011, from ABI/INFORM Global. (Document ID: 2072156651).

24. Tannenbaum, R. \& Hanna, R.W. (1985) Holding on, letting go, and moving on: Understanding a neglected perspective on change. In Margulies, N. \& Massarik, F. (eds.) Human Systems Development. San Francisco, CA: Jossey-Bass, 95-121.

25. Thomas, C.W. and Parish, J. (1999) Co-Sourcing: What's In It For Me? http://www.aicpa.org/pubs/jofa/may1999/thomas.htm

26. Viator, Ralph E. (1999). An analysis of formal mentoring programs and perceived barriers to obtaining a mentor at large public accounting firms. Accounting Horizons, 13(1), 37-53. Retrieved February 16, 2011, from ABI/INFORM Global. (Document ID: 39719220).

27. Volcker, P and Levitt, A. (2004) In Defense of Sarbanes-Oxley, The Wall Street Journal, June 14, A16.

28. Young, G. (2002) New Guidance on Audit and Attest Documentation, CPA Journal, (November). http://www.nysscpa.org/cpajournal/2002/1102/dept/d115002.htm 


\section{TEACHING NOTES}

Internal Control And Accounting Systems Documentation: A Case Study

\section{DISCUSSION QUESTIONS AND ANSWERS}

We believe that that an effective teaching approach developed by Naumes and Naumes (2006) as a three step process works well by 1) asking students to come to class with a structure for Smith's presentation, 2) break them into groups to discuss their respective outlines for her presentation and 3) have the groups report back to the overall class. In the final step we would keep track of the areas identified and are not surprised when the resulting list goes beyond the four sections presented below.

1. What resources did Smith have available to her that could have better prepared her for her internship experience and understanding the Sarbanes-Oxley Act as well as the role of the PCAOB?

There is a wealth of resources available to someone in Smith's position. Textbooks can provide an initial foundation of knowledge, and generally act as an excellent starting point. Internal Controls have long been a substantial part of any systems or auditing course and as such the development and testing of these controls should be addressed in many contemporary textbooks. Journal articles represent a contemporaneous source of information. Given the popularity of SOX, articles related to internal controls, suggested implementation schedules, and potential problems have run prevalent in accounting and auditing journals. This is a good opportunity to expose both graduate and undergraduate students to the more popular academic and professional journals which include: The Journal of Accountancy, The CPA Journal, Accounting Horizons, Internal Auditor and Internal Auditing. Keeping up to date on current journal articles and the issues therein would have better prepared Smith for her experience. We would also direct graduate students to both the Ribstein (2002) Journal of Corporation Law article and the Briaotta (2004), Audit Committee Handbook as either course or case supplements to help to better understand the context of Sarbanes-Oxley.

Another potential and perhaps under-used resource for Smith would be her fellow classmates. Internships are a normal part of any accounting program, and as such many of Smith's fellow classmates more than likely had experience in at least one aspect of a 404 implementation. Professors in her program also would have been a viable alternative for information. A large part of an academic's responsibilities relate to keeping informed of current events in their respective field. Discussing her upcoming opportunity with some of her professor's may have yielded Smith additional insight into her impending responsibilities. Finally, any contacts that Smith made with accounting professionals while in school could have provided information for her. Contacting those working in the field would have given Smith another alternative source of information.

2. Describe the importance of system and/or audit documentation, overall and specifically when dealing with internal auditing and internal controls.

The primary purpose of system documentation in an audit deals with the ability to re-perform the work done by the internal auditor. This becomes invaluable in situations where an auditor's work is questioned or evaluated. Documentation in working papers provides evidence of the competency and appropriateness of any procedures performed. As a result, documentation should be specific enough for anyone reviewing the work to easily follow the trail of procedures performed. Documentation should include records of planning and performing work, any audit evidence obtained during testing procedures, and should support the results and conclusions of the testing.

When dealing with internal auditing and assessing internal controls, documentation takes on a heightened level of importance. Because of the stringent requirements of SOX 404, external auditors need to scrutinize the work done by the internal audit department. Thus, to avoid unnecessary time consuming inquiries or requests from external auditors, documentation should be thorough and complete throughout testing procedures. 
As CPA firms began to outsource internal auditing, the line between internal auditing and external auditing begun to blur. Further, in many venues - including at EntaMove Corporation in particular, Internal Audit was viewed as an area to create cost savings. As a result, we think that this is a good opportunity to discuss the role of Internal Audit as part of SOX 404 implementation as well as their independence role and relationship with both the Board of Directors and the External Auditor. Further, we think that this is an excellent opportunity to discuss contemporary audit failures. By bringing in these the instructor can also talk about the SOX requirement on record retention that resulted specifically from the destruction of documents by Arthur Anderson on the Enron engagement. We would recommend that this would be an excellent opportunity to examine the impact of organizations who received an adverse opinion on SOX (c.f. Bulkeley and Tomsho, 2005). Finally, we recommend that the instructor use a contemporary accounting scandal as a springboard to discussing the importance of independence of all players in the financial reporting process: internal auditor, external auditor, board of directors, audit committee, financial analysts and the media.

\section{What are the perceived benefits of a mentor in an organization, and what responsibilities does management have for establishing a mentoring program?}

There are several key benefits to mentoring, some more apparent than others. Mentors serve in the obvious capacity of acclimating a new hire into an organization. This may involve showing an individual around or giving them important contact information. They also, however, offer an insight for a new hire into the culture of an organization. This may include advice on the less obvious aspects of a firm, including the de facto requirements of an organization (i.e. how late to stay, who to know, what not to do). This advice, depending on the structure of an organization, may prove more useful than any other a new employee may receive. In their classic 1985 article on mentoring Dirsmith and Covaleski found that informal mentoring in large public accounting firms played a limited role in helping employees to understand the power and politics of these organizations. Yet, since this time public accounting firms have continued to encourage employees to develop mentoring relationships (Viator, 1999). Further, in extending the work on mentoring, Sellers and Fogarty (2010) found evidence in their small study of former Arthur Andersen employees that "the socialization that has converted the uninitiated student into a midcareer accountant carries over into subsequent engagements with other organizations." (714) For this reason, it would seem critical that programs set up to help new employees to assimilate into the organization through obtaining work related knowledge can take place in one of three ways: formal training, socialization and mentoring (Bozeman \& Feeney, 2007)

To mitigate the potential for turnover, it behooves an organization to establish mentoring programs for new employees. This offers a chance for the employee to begin both their professional and social journey, with someone to act as a guide. Further, in an organization such as EntaMove where Melissa found herself, the importance of mentoring could prove to be quite important, particularly when understanding power and politics. This effect can also be impacted by the sex of the mentor/mentee (Ortiz-Walters, 2009). Considerable thought should be given in the pairing process, as similar social and demographic backgrounds may help the mentoring relationship flourish. Management responsibility, however, should expand beyond just pairing mentors and mentees, but should also address follow-up strategies, constant review of the process, and tracking the long term effects of the program. This is becoming more and more important in staff retention programs (c.f. Sellers and Fogarty, 2010). As a result we would like to make sure that students understand the role of mentoring and how it could or could not end up on their future careers whether this is formal or informal.

\section{What is management's role in an organization, relative to enacting and communicating change?}

Change often proves a difficult task at the individual level, however, the difficulty compounds when dealing with a global organization. Large implementation efforts, such as going public and/or coming into Section 404 compliance, require a cultural change within an organization to be truly effective. Section 404 requirements impact nearly every aspect of an organization's operations, from the security in an inventory warehouse to the processing of payables. As a result, the need for change must permeate through to these operational areas, a task that requires a change in thought process as well as actions. There has been a significant amount of complaining about the cost of compliance on organizations. As a result we think that this is an opportunity to discuss the cost and benefits of the Act. The WSJ article by Volcker and Levitt (2004) gives a view somewhat contrary to industry and should provoke an excellent discussion. 
In order to truly change a thought process, employees must understand the importance of the change, and how it will impact the long term sustainability of the company. This is ultimately management's highest priority, to relay and instill this need for change, and truly understand its overall importance. This task is done most effectively by communication. Communication can come in verbal or written form, and may come in a variety of venues. Notices can be posted throughout the office, mass emails, or organized meetings. Additionally, less overt messages can be sent to employees, including simply instructing upper management to lead by example or talking with employees in an informal setting. Only when all functional employees fully understand this need for change (as communicated by management), can change at the cultural level truly exist. In accounting coursework, faculty often fails to instantiate to students how accountants are perceived outside the accounting function. This case gives faculty an excellent opportunity to discuss the importance of team building and change management as important to the accounting and systems implementation process.

This would be an excellent opportunity to discuss the implications of SOX provisions for non-SEC registrants and non-profit organizations. Particularly in a graduate class, we would recommend giving students an assignment to investigate whether any states have required that non-profit organizations adopt any of the SOX legislation - and in particular Section 404 (c.f. Connelly, 2003). This would give the instructor an excellent opportunity to discuss the regulation of non-profit organizations by the individual state attorney generals and the IRS. In addition, this offers instructors a nice opportunity to segue into regulation of the accounting profession by individual states.

We would also recommend having students follow-up to see if companies have de-listed from the exchanges because of the cost of SOX compliance. Evidence of this would offer an excellent opportunity to discuss the impact of accounting change on organizations. This is also a good opportunity to discuss the need for SOX compliance by organizations such as state and local organizations, which are not involved in the equity markets but are increasingly being required by auditors to be SOX compliant due to their participation in the debt markets. Finally, we believe that this is also an opportunity to segue into a discussion of the role of Boards of Directors and Audit Committees in particular (c.f. Braiotta, 2004). Because many non-profit (NFP) directors are finding themselves subject to SOX in their fulltime jobs might influence their desire to have aspects of SOX implemented in the NFP both to improve accountability and transparency and to reduce director liability.

We think this case lends itself quite well to role playing and would suggest that instructors consider the following scenarios:

- $\quad$ Arthur Levitt and Paul Volcker vs. Corporate America on the advantages vs. disadvantages of SarbanesOxley compliance requirements for publicly traded companies.

- $\quad$ Richard Scrushy/Ken Lay/Bernie Ebbers/Dennis Kozlowski/John Rigas vs. Stockholders on the internal control requirements and transparency of the Act.

We would divide the groups into teams and have them research the various positions of each constituency. We believe that making students understand a position that hindsight makes less acceptable will help them to question these positions as they arise in the workplace.

\section{RELEVANT RESEARCH}

\section{Mentoring Relationships}

The incessant use of mentoring structures in Corporate America speaks to their perceived usefulness; however, limited research speaks to their tangible benefits. Joiner, Bartram and Garaeffa (2004) offer this connection, in terms of career success, firm commitment, and turnover intentions. In times where turnover can cost a considerable amount to an organization, any structure that can mitigate this risk can be useful and indeed valued. Research findings indicate that a formal mentoring program enhances an individual's perceived career success and organizational commitment. These factors, both individually and combined, are significantly negatively correlated to employee turnover. Thus, housing an effective mentoring program, organizations can hope to enhance the long term sustainability of an employee. 
Herbohn (2004) explores this concept, dealing more specifically with accountants. Herbohn examines the effects of mentoring, with respect to turnover intentions and job satisfaction, among other factors. Herbohn found that indeed, accountants involved in mentoring relationships had fewer intentions to leave their firm, and likewise had a higher overall job satisfaction. Thus, it seems that this relationship expands into the realm of accounting, offering support for both accounting firms and other organizations alike. Perhaps one of the most significant finding was recently published by Sellers and Fogarty (2010) who found evidence to suggest that the first employment experience could become critical in predicting career performance.

\section{Audit Documentation}

For the purposes of this case, the Public Company Accounting Oversight Board Auditing Standard No. 3: Audit Documentation should provide the foundation for understanding documentation requirements. While officially the PCAOB's authority rests with public companies, many large auditing firms have adopted its strategy for all client documentation. Colbert (2005) suggests likewise, that for efficiency purposes internal audit documentation should also be structured to conform to AS No. 3. Additionally, the goals and objectives described in AS No. 3 capture the inherent purpose behind audit documentation in general, and as such ensure in any situation documentation adequacy and consistency.

\section{COMMUNICATION AND CHANGE}

There has been substantial research conducted relative to enacting change in an organization. Tannenbaum \& Hanna (1985) suggest that organizational level change requires change on the individual level. Some of the more contemporary research, however, suggests that identification also plays a significant role in aiding the change process. That is, when an employee internally identifies itself with the organization it works for, this will more easily facilitate the change process. Chriem (2002) offers this communication based approach to creating identification in employees, communication that is issued and supported at the management level. Chriem (2002) further argues that in order to enact change in a individual, management must de-identify an employee with the organizations previous culture and characteristics, and re-identify them with the new ones. This is accomplished through the idea of confluence, where ideals of the past (the processes that the employee is comfortable with) is slowly dissolved, offering a gradual progression into those new ideals or processes. This way, employees can slowly give up their familiar, anchored activities into those new ones that management desires, without a cultural shock. The success of this theory, however, relies on management communication for its effectiveness. Pfeffer (1981) provides the framework that management communication acts as the catalyst for identification, and developing a shared set of values within an organization. Thus, it is easy to understand the overall importance of management communication, as this will ultimately determine the ability of the individual to 1) identify with an organization, and 2) move with the organization (i.e. shift identifications to the new organization).

For any manager involved in a 404 implementation, the connection with the above mentioned research becomes all too apparent. Every aspect of an organization may be subject to change based on becoming SOX compliant for reporting purposes. The accounting clerk, for instance, who has been performing and reviewing bank reconciliations at her leisure, must now deal with segregation of duties and efficient completion of work issues. Thus it is important that management ensure identification of the clerk with the organization, communicate the organizational level change (i.e. the need for a better control structure) and the employee will begin to understand the motivation behind the necessary changes. 


\section{NOTES}

